\title{
Why are nanomaterials different and how can they be appropriately regulated under REACH?
}

\author{
Kathrin Schwirn*, Lars Tietjen and Inga Beer
}

\begin{abstract}
Background: For nanomaterials, not only their chemical composition but also their morphological properties and surface properties determine their characteristics. These properties do not only differ in comparison to the corresponding bulk material but also between different nanoforms of the same substance. Changes in these physico-chemical characteristics can cause changes in chemical properties, reactivity, (photo-) catalytic activities and energetic properties and in turn alter their (eco-) toxicity, fate and behaviour in environmental media and toxico-kinetics. Registration, Evaluation, Authorisation and Restriction of Chemicals (REACH) deals with chemical substances in general and although there are no special provisions that explicitly refer to nanomaterials, they are principally covered by REACH. In October 2012, the European Commission published the Second Regulatory Review on Nanomaterials. In February 2013, the REACH Review from the European Commission was published. Both papers address questions about the regulation of nanomaterials in REACH. The Commission proposes to improve the future situation by adaptation of the REACH Regulation. However, the European Commission plans to revise the annexes only and not the main text of the regulation.

Results and conclusions: In this publication, the authors present their considerations and recommendations on how REACH can adequately be adapted to nanomaterials. In the author's view, the bulk form and nanoforms of the same chemical composition should be treated as the same substance in the context of REACH. However, the regulation of nanomaterials under $\mathrm{REACH}$ has to meet specific requirements. Taking into account the plurality of physico-chemical characteristics and resulting changes in the hazard profile, an approach must be found to adequately cover nanomaterials under REACH. Accordingly, the REACH information requirements have to be adapted. This includes lower tonnage thresholds for different REACH obligations (e.g. registration, chemical safety report) which are justified by highly dispersed use together with low mass application, linked with the uncertainties regarding (eco-) toxicity, environmental fate and exposure. If the physico-chemical characteristics of different nanoforms of the same substance differ in a relevant manner they have to be considered separately for further test performance and REACH requirements.
\end{abstract}

Keywords: REACH; Chemicals regulation; Nanomaterials

\section{Background}

Speciality of nanomaterials and the challenges regarding their assessment

According to the European Commission (EU COM), the global quantity of nanomaterials is around 11.5 million tonnes with a market value of roughly 20 bn $€$ per year [1]. Nanomaterials cover a heterogeneous range of materials including inter alia inorganic metal and metal oxide nanomaterials, carbon-based nanomaterials and polymeric

* Correspondence: Kathrin.Schwirn@uba.de

Federal Environment Agency, WoerlitzerPlatz 1, Dessau-Rosslau 06844, Germany particulate materials in a variety of forms. A wide range of nanomaterials is already available on the market, and nanomaterials for future applications like e.g. targeted drug delivery systems, novel robotic devices, moleculeby-molecule design and self-assembly structures are in development. Now then, what makes nanomaterials, in particular manufactured nanomaterials, so special that they should be explicitly addressed under the European Chemicals Regulation REACH [2].

For nanomaterials, not only their chemical composition but also their morphological properties like size, shape and surface properties determine their characteristics.

\section{黑 Springer}


These parameters can affect the chemical properties, reactivity, (photo-) catalytic activities of a substance as well as energetic properties and their confinement. The properties of nanomaterials do not only differ from their bulk counterpart but also between different nanoforms of the same chemical substance and hence do their effects and behaviour. The property changes can lead to e.g. differences in cell penetration, in the mode of action and in the toxicity level, and may also vary in dose-response relationships describing toxicity. Subsequently, the question arises how these specific properties influence behaviour and effects in the environment and whether existing risk assessment and mitigation methods can be applied to nanomaterials without further a do.

Studies show that often nanomaterials can penetrate biological systems, like e.g. cell walls and membranes, and remain within the cell [3]. It is assumed that in this way a higher amount of a substance in comparison to the corresponding bulk form or substances that normally would not pass through barriers can enter the cell and may lead to a variety of toxic impacts. The following processes mediating cell toxicity can be possible: nanomaterials can excite coupled effects by causing ion toxicity together with particle toxicity; nanomaterials can delay and prolong the occurrence of toxic effects resulting from depot properties, or enable the uptake and impact of other toxic substances within the cell by a carrier effect [4-8]. Thus, the toxic consequence of cellular uptake of nanomaterials is hard to predict.

Due to the size dependence of the energy band gaps of materials, the energy band gaps of various nanomaterials correspond with the energy levels of important biological reactions, resulting inter alia in an increased formation of reactive oxygen species and subsequently oxidative stress in organisms [9-11]. Additionally, histological analysis upon nanomaterial exposure showed abnormalities in tissues of different organs of fish [12-14]. Furthermore, scientists observed mechanical stress onto aquatic organisms as well as influences on the reproduction of invertebrates like earth worms $[15,16]$. Photocatalytic active nanomaterials show a clearly higher toxicity under UV irradiation to aquatic organisms than observed for same test conditions without UV irradiation $[17,18]$. In our view, observations like these cannot be neglected for environmental risk assessment.

Previous studies on the effects of nanomaterials on the environment mainly focused on toxicity for aquatic organisms and the behaviour in the aquatic environment. However, nanomaterials tend to exhibit agglomeration and sedimentation. Therefore, an increased exposure of sediment and soil organisms is expected, but less information is available on the effects on soil and sediment organisms. This is due to the methodical challenges, like the absence of the possibility to detect and observe the nanomaterial and its behaviour in a complex system. Moreover, data on long-term effects of nanomaterials to organisms in the environment, effects on populations and communities (e.g. as determined in mesocosm studies), environmental monitoring as well as data regarding bioaccumulation and biomagnification are rare. Data on effect monitoring is not available so far.

A further obstacle in the assessment of nanomaterials regarding environmental risks is the low comparability and reproducibility of available study results. This is caused by the high variety of existing and in particular investigated nanomaterials, which differ in composition and their production process, variations in sample preparation and characterisation, which can influence the results significantly. Overall, in many cases, the investigated nanomaterials as produced as well as in media are neither sufficiently described nor characterised. This is of importance for instance for nanosilver where the release of silver ions depends on the intrinsic stability against dissolution or other alteration and the composition of the surrounding media [19-21].

The environmental fate of nanomaterials is generally very complex, but this complexity cannot be sufficiently investigated with the currently available standard tests. For instance, test guidelines on dissolution and determination of the partitioning coefficient $\log K_{\mathrm{OW}}$ as well as adsorption/desorption in soil compartment are not applicable. There also is a lack of guidelines for the determination of dispersion behaviour and transformation in environmental media, respectively. These shortcomings were identified amongst others by the Organisation for Economic Co-operation and Development (OECD) Expert Meeting in the framework of the OECD Working Party of Manufactured Nanomaterials, held in January 2013 in Berlin [22]. Moreover, tools for exposure estimation cannot be sufficiently applied, as existing input parameters are not suitable for the calculation of the environmental distribution [23,24]. Furthermore, a validation of the results of the predicted environmental concentration (PEC) calculation is currently not possible due to the lack of appropriate techniques and devices in order to determine environmental concentrations.

Due to the particular uncertainties concerning evaluation of the possible risks of nanomaterials for human health and the environment, as well as on the grounds of the precautionary principle, the chemicals legislation needs to be revised. The most important aspect right now is the generation of information. This can be achieved by relatively mild measures. The adaptation of existing test methods and, in particular, the creation of nanospecific information requirements for the $\mathrm{REACH}$ registration are two possible options. In the following chapters, it is described how nanomaterials are currently regulated under REACH. Subsequently, the authors present their considerations and 
recommendations on how $\mathrm{REACH}$ can adequately be adapted to nanomaterials.

\section{Current regulation of nanomaterials under REACH}

Although there are no provisions in $\mathrm{REACH}$ that explicitly refer to nanomaterials, it covers nanomaterials since it deals with substances in general. Therefore, also the basic principle that is laid down in Article 1 (3) 'This Regulation is based on the principle that it is for manufacturers, importers and downstream users to ensure that they manufacture, place on the market or use such substances that do not adversely affect human health or the environment' applies to nanomaterials.

Since nanomaterials are substances within the meaning of REACH, they also have to be registered if the yearly manufactured or imported quantity reaches 1 tonne. As it is not regulated otherwise, a manufacturer/ importer who manufactures/imports not only a nanomaterial but also the corresponding bulk material with the same chemical identity registers the nanomaterial and the bulk material together in one registration. Nanomaterials are not regarded as separate substances within the meaning of the current $\mathrm{REACH}$ rules, but as substances in a certain form. The sum of the quantities (nanomaterial(s) + bulk) is decisive for the calculation of the aforementioned tonnage threshold. If no corresponding bulk material is manufactured or imported by the same registrant, the nanomaterial has to be registered on its own accordingly. However, the registration dossier of the nanomaterial can be a part of the joint submission for the chemically identical substance. For yearly quantities of 10 tonnes or more, a chemical safety report has to be submitted.

Generally, each registrant has the obligation to accurately describe the material that he manufactures/imports or uses and to ensure the safe use of this material. The manufacturer/importer/downstream user that places the bulk material and the nanomaterial(s) on the market is, e. g., obliged to classify and label them differently in case the available data give reason to do so. The questions arise in the details: How does one know if the material is a nanomaterial at all? How does one know if the nanoform on hand has to be treated separately from or jointly with another nanoform?

Many experts are of the opinion that the testing requirements, test strategies and test methods under REACH are in principle applicable to nanoscale substances. However, some adaptations to the specificities of nanomaterials are needed $[25,26]$.

The explanations above show that obligations regarding nanomaterials exist. Nevertheless, e.g. the registration dossiers that ECHA has received so far reveal that there is an obvious deficit. Hardly any information about nanomaterials was contained or retrievable in the dossiers. In addition for the few information on nanomaterials provided, the responsible registrants did mostly not indicate which nanoform was tested or which nanoform the information referred to, respectively [27]. This shows that the obligations regarding nanomaterials are either not clear enough or the current regulation offers too many loopholes, or both. Also, for the second registration period which ended 31 May 2013, only four substances were registered as nanomaterials [28].

ECHA is working on clarifications by adapting guidance documents, forming advisory groups, conducting projects, organising trainings and webinars and much more. Nevertheless, the discussion is still ongoing whether this is enough or whether the regulation itself has to be adapted.

\section{Activities in the EU}

On the European level, the discussion about nanomaterials has been ongoing for several years. In May 2004, the European Commission adopted the Communication 'Towards a European Strategy for Nanotechnology' [29]. The Communication proposed actions to promote a strong role of Europe in nanoscience und nanotechnology. The communication also covered the need to address potential risks for health and environment. In June 2005, the European Commission presented an action plan 'Nanosciences and nanotechnologies' for 2005 to 2009.

In 2008 the European Commission published a (first) regulatory review of EU legislation with respect to nanomaterials. The main conclusion was 'Current legislation covers in principle the potential health, safety and environmental risks in relation to nanomaterials. The protection of health, safety and the environment needs mostly to be enhanced by improving implementation of current legislation'.

In 2009 the European Parliament responded to the European Commission Communication in a resolution [30] and did the following:

1. Called for a regulatory and policy framework that explicitly addresses nanomaterials

2. Called on the Commission to review all relevant legislation

3. Called for an inventory and product labelling

4. Called specifically on the Commission to evaluate the need to review REACH concerning inter alia:

(a) Simplified registration for nanomaterials manufactured or imported below 1 tonne

(b) Consideration of all nanomaterials as new substances 
(c) A chemical safety report with exposure assessment for all registered nanomaterials

(d) Notification requirements for all nanomaterials placed on the market on their own, in preparations or in articles

While first nanospecific provisions were integrated in the Regulation (EC) no. 1333/2008 on food additives, specific provisions for nanomaterials were also created in some other legislation, which was approved in the last years such as biocidal products (Regulation (EU) no. 528/ 2012) and cosmetics regulation (Regulation (EC) no. 1223/2009). The central chemical regulation $\mathrm{REACH}$, however, was not adapted to better address nanomaterial.

Indeed, the European Commission started projects to investigate the needs for additional provisions. Based on the outcomes of the REACH Implementation Projects [Information Requirements (RIP-oN 2); Chemical Safety Assessment (RIP-oN 3)], ECHA prepared appendices to the Guidance on Information Requirements and Chemical Safety Assessment (IR \& CSA). In the project on Substance Identification of Nanomaterials (RIP-oN 1), no consensus between the stakeholders was reached on whether parameters like size, shape and surface treatment of a nanomaterial can be regarded as a so-called identifier (changes in parameters trigger a new substance) or 'characterizer' (changes in parameters do not trigger a new substance, but another form of a substance).

The European Commission published a Second Regulatory Review on Nanomaterials in October 2012 and the REACH Review in February 2013 [1,31]. These reports depict the Commission's main conclusions regarding nanomaterials: According to the European Commission, the $\mathrm{REACH}$ registration and proof of safe use for nanomaterials should be based on a case by case approach, and each type of nanomaterial should be clearly described. Since only very limited information about nanomaterials was provided in the first registration period by December 2010, the Commission proposes to improve the situation in future by adaption of the REACH Regulation. The Commission initiated a public consultation on how the annexes of $\mathrm{REACH}$ could be amended to ensure that nanomaterials are registered more clearly under $\mathrm{REACH}$ and that the safe use of nanomaterials is adequately demonstrated within the registration dossiers, as part of an impact assessment in May 2013 [32]. The consultation comprised five potential policy options which were measured against a baseline that assumes no new policy actions. The consultation asked how respondents consider the potential impact of the options on cost, safety and overall efficiency of the regulatory process based on 37 main questions and 183 subquestions. The consultation closed mid of September 2013. The initial results of the consultation were presented at the Member State experts' meeting in October 2013. In total, 142 responses to the questionnaire were submitted. Forty-nine percent of the replies were made by industry, while $12 \%$ were from national authorities, and 7\% from consumer associations and non-governmental associations. The results were split into two opposites. While $38 \%$ prefer a loosening of $\mathrm{REACH}$ for nanomaterials, $31 \%$ called for tougher information requirements. The final results of the impact assessment are now expected for early 2014 [33].

However, the Commission plans to revise the annexes only and not the main text of the regulation. The Commission justifies this approach by being able to use the faster and lighter comitology procedure and by avoiding to re-open the general $\mathrm{REACH}$ discussion. This approach was supported by a majority of Member States, at least as a first step. In our view one reason for the Commission to choose the comitology procedure is that the Commission has a stronger position than during the ordinary legislative procedure.

Similar discussions on regulatory frameworks take place in other countries and in academia [34-36]. However, this publication focuses on the ongoing discussion in Europe.

In our opinion, the planned amendments and, in particular, the refusal regarding the adaptation of the main text of $\mathrm{REACH}$ are not sufficient in order to receive adequate, meaningful and relatable information on nanomaterials. In the interest of legal clarity and certainty, we propose that the definition for nanomaterials should be integrated in Article 3. Furthermore, additional amendments of the $\mathrm{REACH}$ regulation should be conducted which will be presented in the following chapters.

\section{Results and discussion}

There is a high variety of existing nanomaterials which differ in chemical composition, size, shape, crystallinity and surface modification. Figure 1 shows exemplarily a small excerpt of the variety of possible nanomaterials. Taking into account this plurality of physico-chemical characteristics and resulting changes in the hazard profile, an approach must be found to adequately cover nanomaterials under REACH. There are two approaches conceivable to cover nanomaterials under REACHtreating them as substances on its own or as specific forms of a substance.

\section{Nanomaterial as a substance on its own}

The bulk form and nanoforms of the same chemical composition could be treated as different substances within the meaning of REACH. In the context of RiP-oN 1 , this approach was called 'size as an identifier'. To be more precise, such an approach could use the change of different parameters (e.g. differences in size, shape, surface) to decide on the regulatory substance identity. 
i)

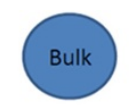

ii)

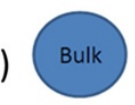

iii)

no bulk form
existing

Explanation:
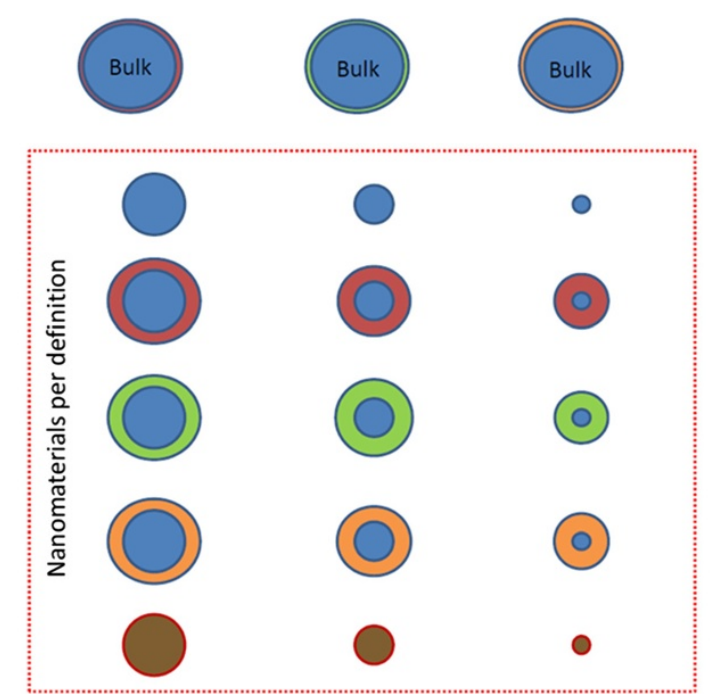

core substance $\mathrm{A}$

core substance $B$ substances of surface modification

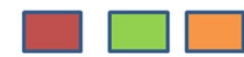

Figure 1 Schematic illustration of different forms of a substance. (i) Bulk form with different surface modifications; (ii) bulk form and nanoforms of the same substance, nanoforms shown with different sizes and different surface modifications; (iii) nanoforms of a substance with different sizes without having a corresponding bulk form (e.g. fullerenes, carbon nanotubes).

REACH and in particular the classification, labelling, packaging (CLP) Regulation [37] base in general on the assumption that a substance has an intrinsic hazard profile independent from the manufacturing process. Thus, REACH information can be shared between the registrants of the substance, and the hazard classification based on the CLP Regulation should correspond (e.g. agreed entry, harmonised classification). However, this approach has limitations already for bulk materials. For example, bulk materials of the same substance can differ in their hazard profiles based on impurities or macroscopic particle size, leading to different classifications under the CLP Regulation. As already mentioned above, different nanomaterials of the same chemical composition often have very different properties and, subsequently, can differ in their hazard profile. This condition for instance can be utilised to define nanomaterials as substances on their own. In a paper from Competent Authorities for REACH and CLP (CARACAL), it is described that indeed in some cases the nanoform could be treated as a substance on its own: 'In the case of substances at nanoscale, it is possible that some substances which in the past have been identified by the same EINECS number may have to be considered as different substances for the purpose of REACH' [38]. However, the paper does not provide criteria for this decision.

In the context of this approach, there is a need for clear criteria to avoid a split-up in many substances with small tonnages below the REACH triggers for registration requirements due to the variability of nanomaterials. The argument of the CARACAL paper based on the guidance for data sharing is 'whether or not data sharing would give a meaningful result' [39]. Some stakeholders are in favour of considering nanomaterials as substances on their own. If even the different nanoforms of a substance were treated as different substances, such an approach would need very low tonnage triggers for the registration and data obligations in REACH. A proposal from KemI gives an impression of some of the necessary changes [40]. KemI proposes to regulate nanomaterials by an individual regulation, which supports the existing $\mathrm{REACH}$ regulation. Nanomaterials shall be considered as substances of its own with a registration starting from $10 \mathrm{~kg} / \mathrm{a}$. However, the KemI proposal does not include an approach how to differentiate between different nanomaterials of the same chemical composition.

In summary, for the legal implementation of such an approach, clear criteria to decide if two nanomaterials of the same chemical composition are different substances in the meaning of REACH are necessary. It must be carefully considered what the consequences of the aforementioned change of the substance definition are for other pieces of legislation that address substances as such. Furthermore, such an approach would need a comprehensive review of the diverse instruments of the REACH regulation in order to ensure the workability of the instruments like data sharing, substance evaluation, information requirements and chemical safety assessment. 


\section{Nanomaterials as specific forms of a substance}

Basically the same requirements for nanomaterials can be implemented with a different approach which is more in line with the substance definition and structure of the REACH regulation. The bulk form and nanoforms of the same chemical composition could be treated as the same substance in the context of REACH. This approach was called 'size as a characterizer' in the discussion of RIP-oN1.

Also in this case, the regulation of nanomaterials under REACH has to meet specific requirements. This includes a differentiated consideration of the bulk form and nanoform and the different nanoforms of the same substance respectively. Separate risk assessments shall be performed for the different nanoforms. An adequate handling of surface-treated nanomaterials has to be defined. Tonnage bands and information requirements need to be adjusted, and even the role of the downstream user has to be reconsidered. For all these requirements, the burden of proof has to be on the side of the registrant. In the following sections, we will present some corner stones of the proposal published by the German federal authorities responsible for REACH [41]. The concept presents considerations how REACH could be amended to adequately cover nanomaterials.

One important aspect is the substance identity. Generally, for a well-defined substance under REACH, the substance identity is defined solely by the molecular structure and chemical composition. Bulk and nanomaterial with the same molecular structure are chemically identical. This means that the bulk form and nanoform of a substance generally have to be registered in the same dossier. Therefore, the concept follows the characteriser approach.

Nevertheless, special characteristics concerning (eco-) toxicology, toxico-kinetics and environmental fate, together with the existing uncertainties and special features with regard to mode of action, necessitate requirements which go beyond those laid down in REACH to date. The information requirements under $\mathrm{REACH}$ therefore have to be adapted.

\section{What should be the requirements for nanomaterials under REACH?}

Nanomaterials have a low bulk density. This comes along with a typically high technical effectiveness caused by a high specific surface area and changes of reactivity, respectively. These characteristics together allow a wide dispersive use by a low mass application of the substance. Therefore and because of the uncertainties regarding (eco-) toxicology, environmental fate and exposure information requirements should already apply at lower tonnage bands. Following the structure of the REACH regulation for tonnage-based triggers, it would be reasonable to stipulate a simplified registration for nanomaterials starting from $100 \mathrm{~kg} / \mathrm{a}$, which requires information about substance identity, characterisation and use. Starting at a tonnage band of $1 \mathrm{t} / \mathrm{a}$, requirements regarding (eco-) toxicology listed in a new nanospecific annex have to be fulfilled. This nanospecific annex covers information requirements for the different tonnage levels. With respect to environment, these nanospecific information requirements subject chronic tests instead of acute tests at lower tonnage levels. Regarding the presumable partitioning of nanomaterials within the environment, appropriate target organisms have to be taken into account. That means information requirements must cover toxicity to sediment and soil organisms at lower tonnages. Furthermore, low water solubility as the exclusive waiving criterion for aquatic testing is not appropriate for nanomaterials, since also insoluble nanomaterials can show effects in the environment. Moreover, a chemical safety report, which considers every nanoform separately, has to be submitted if the sum of all nanoforms of a substance reaches the quantity of $1 \mathrm{t} / \mathrm{a}$. Future adjustments regarding assessment concepts and test guidelines have to be taken into account.

Information requirements should first of all include a comprehensive characterisation of the nanoforms. This means that for each nanoform within a substance registration in addition to the identification of the chemical composition for substance identity, a characterisation of morphological parameters (e.g. size, shape, and crystal structure), surface properties (e.g. charge, surface reactivity, functional group, dispersability) and its solubility in different media would be necessary. However, it has to be noted that the further development and standardisation of reference methods for characterisation are still ongoing.

The registrant can use the information on the nanoforms' characteristics to ascertain if different nanoforms of a substance can be considered jointly or separately for the fulfilment of information requirements. This decision should be based on the aforementioned physical and chemical parameters and whether these differ or equal in a relevant way. A difference should be considered as relevant if it is likely that it leads to a change of the hazard profile. If nanoforms of a substance differ in a relevant way, information requirements have to be fulfilled separately for the individual forms. In a further step, an endpoint-specific waiving and read across between different nanoforms of the same substance should be possible on a scientific basis. The process of examination whether different nanoforms can be considered jointly or separately for information requirements is illustrated in Figure 2.

\section{How can surface-treated nanomaterials be handled under REACH?}

For nanomaterials, the surface to volume ratio dramatically increases with decreasing size and thus the surface plays a major role in the interaction with its surroundings. 


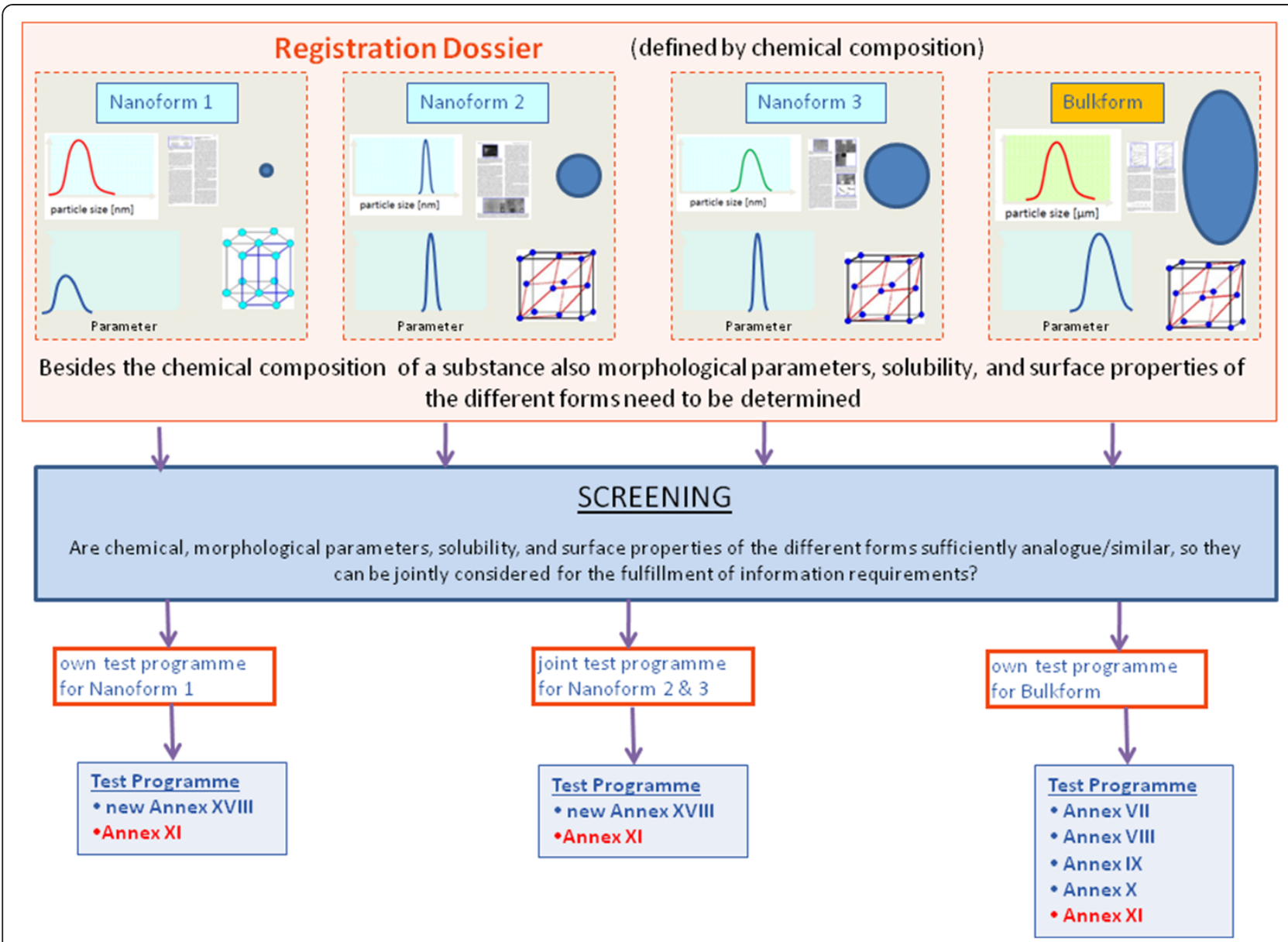

Figure 2 Examining different nanoforms to be joined or separated for the fulfilment of information requirements. Annex XVIII represents the proposed new Annex with nanospecific and tonnage depending information requirements.

Changes of surface properties (e.g. by modification with other substances) would result in the change of the nanomaterial's behaviour and resulting effects. Therefore, surface properties and their changes must not be neglected in the consideration of different forms of nanoscaled substances.

On the one hand, the conventional approach is to register surface-treated and surface-treating substances separately. This approach can be used for substances for which surface is of minor importance, but it is not appropriate for nanomaterials since nanomaterials have a very high surface to value ratio which increases with decreasing particle size. On the other hand, it is discussed that each surface-treated substance is regarded as a substance on its own. However, there are diverse substances existing as nanomaterials. Additionally, these can be surface treated with a variety of different substances leading to a countless number of new substances. Thus, the question appears how surface-treated nanomaterials can be considered under REACH while avoiding the aforementioned splitting into numerous new substances?
A possibility could be to define a surface-treated nanomaterial as a separate nanoform of the untreated substance. We propose to apply the substance identity approach with the $80 \mathrm{wt} . \%$ criterion. If the surfacetreated nanomaterial consists of at least 80 wt.\% of the core material, it fulfils this criterion and is regarded as a separate nanoform of the core material. If the surfacetreated nanomaterial consists of less than $80 \mathrm{wt} . \%$ of the core material, it does not fulfil the criterion and has to be defined as a new substance. Following this approach the registrant has to demonstrate that the different nanoforms can be jointly considered or have to be separately considered for further test performances and REACH requirements.

In general, the implementation of this approach requires the adaptation of the articles and the annexes of REACH. Especially, demands like a simplified registration for nanomaterials starting from $100 \mathrm{~kg} / \mathrm{a}$ and a chemical safety report for quantities of $1 \mathrm{t} / \mathrm{a}$ or more can only be realised by amending the main text of $\mathrm{REACH}$. Other demands like adapted information requirements, the 
separate consideration of different nanoforms for testing obligations and for the chemical safety report, the possibility of scientifically justified waiving and read across, and the handling of surface-treated nanomaterials could at least partly be implemented by amending the $\mathrm{REACH}$ annexes and guidance documents only.

\section{Conclusions}

On the European level, there are ongoing discussions whether nanomaterials should be treated as substances on their own or as a specific form of a substance and what requirements for nanomaterials under $\mathrm{REACH}$ should look like. In our view, the bulk form and nanoforms of the same chemical composition should be treated as the same substance in the context of REACH. However, the regulation of nanomaterials under REACH has to meet specific requirements.

For nanomaterials, not only the chemical composition but also morphological properties and surface properties determine the special characteristics. These properties do not only differ in comparison to the corresponding bulk material but also between different nanoforms of the same substance. Changes in the physico-chemical characteristic can cause changes in chemical properties, reactivity, (photo-) catalytic activities and energetic properties and in turn alter their (eco-) toxicity, fate, behaviour in environment media and toxico-kinetics. Taking into account this plurality of physico-chemical characteristics and resulting changes in the hazard profile, an approach must be found to adequately cover nanomaterials under REACH. This would mean that the $\mathrm{REACH}$ information requirements have to be adapted.

Regarding environmental information, chronic tests instead of acute tests and toxicity to sediment and soil organisms are necessary at lower tonnage thresholds. This is justified by potentially wide dispersive use even by a low mass application linked with the uncertainties regarding (eco-) toxicity, environmental fate and exposure. If the physico-chemical characteristics of different nanoforms of the same substance differ in a relevant manner, they have to be considered separately for the further test performance and REACH requirements. A possibility to handle surface-treated nanomaterials would be to consider them as a separate nanoform of the untreated substance.

\section{Methods}

This study utilized description of the results of the regulatory work regarding the proposal for the adaptation of the $\mathrm{REACH}$ regulation to nanomaterials including literature analysis and taking into account the experiences from regulatory activities.

\footnotetext{
Abbreviations

CARACAL: Competent Authorities for REACH and CLP; CLP: Classification, Labelling, Packaging; COM: European Commission; ECHA: European
}

Chemicals Agency; EINECS: European Inventory of Existing Commercial Chemical Substances; EU: European Union; OECD: Organisation for Economic Co-operation and Development; PEC: predicted environmental concentration; REACH: European Chemicals Regulation EC no. 1907/2006 on Registration, Evaluation, Authorization and Restrictions of Chemicals.

\section{Competing interests}

The authors declare that they have no competing interests.

\section{Authors' contributions}

$\mathrm{KS}, \mathrm{LT}$ and IB contributed in equal parts to this publication. All authors read and approved the final manuscript.

\section{Acknowledgements}

We would like to thank our colleagues from the German Federal Institute for Risk Assessment and the German Federal Institute for Occupational Safety and Health for the productive discussions and joint development of the proposal published by the federal authorities responsible for REACH.

Received: 17 October 2013 Accepted: 28 January 2014

Published: 6 February 2014

\section{References}

1. European Commission: Communication from the Commission to the European Parliament, the Council and the European Economic and Social Committee - second regulatory review on nanomaterials. http://eur-lex.europa. eu/LexUriServ/LexUriServ.do?uri=COM:2012:0572:FIN:en:PDF.

2. European Parliament Council: Regulation (EC) no 1907/2006 of the European Parliament and of the Council of 18 December 2006 concerning the Registration, Evaluation, Authorisation and Restriction of Chemicals (REACH), establishing a European Chemicals Agency, amending Directive 1999/45/EC and repealing Council Regulation (EEC) no $793 / 93$ and Commission Regulation (EC) no $1488 / 94$ as well as Council Directive 76/769/EEC and Commission Directives 91/155/EEC, 93/67/EEC, 93/105/EC and 2000/21/EC. Official J EU 2006, L353:1-849.

3. Navarro E, Baun A, Behra R, Hartmann NB, Filser J, Miao AJ, Quigg A, Santschi PH, Sigg L: Environmental behavior and ecotoxicity of engineered nanoparticles to algae, plants, and fungi. Ecotoxicology 2008, 17:372-386.

4. Poynton HC, Lazorchak JM, Impellitteri CA, Smith ME, Rogers K, Patra M, Hammer K, Allen JH, Vulpe CD: Differential gene expression in Daphnia magna suggests distinct modes of action and bioavailability for $\mathrm{ZnO}$ nanoparticles and Zn ions. Environ Sci Technol 2011, 45:762-768.

5. Neal AL, Kabengi N, Grider A, Bretsch PM: Can the soil bacterium Cupriavidus necator sense $\mathrm{ZnO}$ nanomaterials and aqueous $\mathrm{Zn}^{2+}$ differentially? Nanotoxicology 2012, 6(Suppl 4):371-380.

6. Bilberg $K$, Hovgaard MB, Besenbacher F, Baatrup E: In vivo toxicity of silver nanoparticles and silver ions in zebrafish (Danio rerio). J Toxicol 2012, 293784:9.

7. Sun H, Zhang X, Niu Q, Chen Y, Crittenden JC: Enhanced accumulation of arsenate in carp in the presence of titanium dioxide nanoparticles. Water Air Soil Pollut 2007, 178:245-254.

8. Misra SK, Dybowska A, Berhanu D, Luoma SN, Valsami-Jones E: The complexity of nanoparticle dissolution and its importance in nanotoxicological studies. Sci Total Environ 2012, 438:225-232.

9. Burello $E$, Worth AP: A theoretical framework for predicting the oxidative stress potential of oxide nanoparticles. Nanotoxicology 2010, 5:228-235.

10. George S, Xia T, Rallo R, Zhao Y, Ji Z, Lin S, Wang X, Zhang H, France B, Schoenfeld D, Damoiseaux R, Liu R, Lin S, Bradley KA, Cohen Y, Nel AE: Use of a high-throughput screening approach coupled with in vivo zebrafish embryo screening to develop hazard ranking for engineered nanomaterials. ACS Nano 2011, 5:1805-1817.

11. Zhang H, Ji Z, Xia T, Meng H, Low-Kam C, Liu R, Pokhrel S, Lin S, Wang X, Liao YP, Wang M, Li L, Rallo R, Damoiseaux R, Telesca D, Mädler L, Cohen Y, Zink JI, Nel A: Use of metal oxide nanoparticle band cap to develop a predictive paradigm for oxidative stress and acute pulmonary inflammation. ACS Nano 2012, 6:4349-4368.

12. Frederici G, Shaw BJ, Handy RD: Toxicity of titanium dioxide nanoparticles to rainbow trout (Oncorhynchus mykiss): gill injury, oxidative stress, and other physiological effects. Aquat Toxicol 2007, 84:415-430. 
13. Smith CJ, Shaw BJ, Handy RD: Toxicity of SWCNT to rainbow trout: respiratory toxicity, organ pathologies, and other physiological effects. Aquat Toxicol 2007, 82:94-109.

14. Ramsden CS, Smith TJ, Shaw BJ, Handy RD: Dietary exposure to titanium dioxide nanoparticles in rainbow trout, (Oncorhynchus mykiss): no effect on growth, but subtle biochemical disturbances in the brain. Ecotoxicology 2009, 18:939-951.

15. Dabrunz A, Duester L, Prasse C, Seitz F, Rosenfeldt R, Schilde C, Schaumann $G E$, Schulz R: Biological surface coating and molting inhibition as mechanisms of TiO2 nanoparticle toxicity in Daphnia magna. PloS One 2011, 6(Suppl 5):e20112.

16. Schlich $\mathrm{K}$, Terytze $\mathrm{K}$, Hund-Rinke $\mathrm{K}$ : Effects of $\mathrm{TiO} 2$ nanoparticles in the earthworm reproduction test. Environ Sci Eur 2012, 24:5.

17. $\mathrm{Ma} \mathrm{H}$, Bennan A, Diamond S: Phototoxicity of TiO2 nanoparticles under solar radiation to two aquatic species: Daphnia magna and Japanese medaka. Environ Toxicol Chem 2012, 31(7):1621-1629.

18. Miller RJ, Bennett S, Keller AA, Pease S, Lenihan HS: TiO2 nanoparticles are phototoxic to marine phytoplankton. PLoS One 2012, 7(Suppl 1):e30321.

19. Gondikas AP, Morris A, Reinsch BC, Marinakos SM, Lowry GV, Hsu-Kim H: Cysteine-induced modifications of zero-valent silver nanomaterials: implications for particle surface chemistry, aggregation, dissolution, and silver speciation. Environ Sci Technol 2012, 46:7037-7704.

20. Kennedy AJ, Chappell MA, Bednar AJ, Ryan AC, Laird JG, Stanley JK, Steevens JA: Impact of organic carbon on the stability and toxicity of fresh and stored silver nanoparticles. Environ Sci Technol 2012, 46:10772-10780.

21. Tejamaya M, Römer I, Merrifield RC, Lead JR: Stability of citrate, PVP, and PEG coated silver nanoparticles in ecotoxicology media. Environ Sci Technol 2012, 46:7011-7017.

22. Kuehnel D, Nickel C: The OECD expert meeting on ecotoxicology and environmental fate - towards the development of improved OECD guidelines for testing nanomaterials. Sci Total Environ 2014, 472:347-353.

23. Arvidsson R, Molander S, Sandén BA, Hasselöv M: Challenges in exposure modelling of nanoparticles in aquatic environments. Hum Ecol Risk Assess 2011, 17:245-262.

24. Hansen SF, Baun A, Tiede K, Gottschalk F, Van der Meent D, Peijnenburg W, Fernandes T, Riediker M: Consensus report based on the Nano Impact Net workshop: environmental fate and behaviour of nanoparticles - beyond listing of limitation. http://www.nanoimpactnet.eu/uploads/Deliverables/D2.4.pdf.

25. Hankin SM, Peters SAK, Poland CA, Hansen SF, Holmqvist J, Ross BL, Varet J, Aitken RJ: Specific advice on fulfilling information requirements for nanomaterials under REACH (RIP-oN 2) - final project report. http://ec.europa. eu/environment/chemicals/nanotech/pdf/report_ripon2.pdf.

26. Organisation for Economic Co-operation and Development: Environment Directorate: Preliminary review of OECD test guidelines for their applicability to manufactured nanomaterials. http://search.oecd.org/officialdocuments/ displaydocumentpdf $/$ ?doclanguage $=e n \&$ cote $=e n v / j m / m o n o \% 282009 \% 2921$.

27. European Commission: NANO SUPPORT Project: scientific technical support on assessment of nanomaterials in REACH registration dossiers and adequacy of available information. http://ec.europa.eu/environment/chemicals/nanotech/ pdf/jrc_report.pdf.

28. European Chemical Agency: The outcome of the second REACH registration deadline. http://echa.europa.eu/documents/10162/13126357/ press_memo_reach_2013_en.pdf.

29. European Commission: Towards a European strategy for nanotechnology. http://ec.europa.eu/nanotechnology/pdf/nano_com_en_new.pdf.

30. European Parliament: European Parliament resolution of 24 April 2009 on regulatory aspects of nanomaterials. http://www.europarl.europa.eu/sides/ getDoc.do?type=TA\&reference=P6-TA-2009-0328\&language=EN .

31. European Commission: General report on REACH in accordance with Article $117(4)$ of REACH and Article 46(2) of CLP, and a review of certain elements of REACH in line with Articles 75(2), 138(2), 138(3) and 138(6) of REACH. http:// eur-lex.europa.eu/LexUriServ/LexUriServ.do?uri=COM:2013:0049:FIN:EN:PDF.

32. European Commission: Public consultation on the modification of the REACH annexes on nanomaterials. http://ec.europa.eu/enterprise/sectors/chemicals/ reach/nanomaterials/index_en.htm.

33. European Commission: 13th Meeting of Competent Authorities for REACH and CLP (CARACAL): document CA/36/2013. https://circabc.europa.eu/sd/d/ 1e829ba0-9450-4a08-8b8a-64695a2f6e70/04\%20-\%20CA_36_2013_Nano\% 20IA_v2.doc.
34. Organisation for Economic Co-operation and Development, Environment Directorate: Publications in the series on the safety of manufactured nanomaterials. http://www.oecd.org/science/nanosafety/ publicationsintheseriesonthesafetyofmanufacturednanomaterials.htm.

35. Linkov I, Satterstorm FK, Monica JC Jr, Hansen F, Davis TA: Nano risk governance: current developments and future perspectives. Nanotechnology 2009, 6:203-220.

36. Grieger KD, Linkov I, Hansen F, Baun A: Environmental risk analysis for nanomaterials: review and evaluation framework. Nanotoxicology 2012, 6:196-212.

37. European Parliament, Council: Regulation (EC) no 1272/2008 of the European Parliament and of the Council of 16 December 2008 on classification, labelling and packaging of substances and mixtures, amending and repealing Directives 67/548/EEC and 1999/45/EC, and amending Regulation (EC) no 1907/2006. Official J EU 2008, L353:1-1355.

38. European Commission: Nanomaterials in REACH; paper from the meeting of the REACH competent authorities for the implementation of regulation (EC) 1907/2006 (REACH). http://ec.europa.eu/enterprise/sectors/chemicals/files/ reach/nanomaterials_en.pdf.

39. European Chemical Agency: Guidance on data sharing. http://echa.europa. eu/documents/10162/13631/guidance_on_data_sharing_en.pdf.

40. Swedish Chemical Agency: Draft proposal for a regulation on nanomaterials. http://www.kemi.se/Documents/Forfattningar/Reach/Draft-proposalregulation-nanomaterials.pdf.

41. Umweltbundesamt, Bundesinstitut für Risikobewertung, Bundesamt für Arbeitsschutz und Arbeitsmedizin: Nanomaterials and REACH - background paper on the position of German Competent Authorities. http://www. umweltbundesamt.de/publikationen/nanomaterials-reach.

doi:10.1186/2190-4715-26-4

Cite this article as: Schwirn et al:: Why are nanomaterials different and how can they be appropriately regulated under REACH? Environmental Sciences Europe 2014 26:4

\section{Submit your manuscript to a SpringerOpen ${ }^{\circ}$ journal and benefit from:}

- Convenient online submission

- Rigorous peer review

- Immediate publication on acceptance

- Open access: articles freely available online

- High visibility within the field

- Retaining the copyright to your article

Submit your next manuscript at springeropen.com 